\title{
Monitoring environmental microbiological safety in a frozen fruit and vegetable plant
}

\author{
Aycan CINAR ${ }^{1 \star}$ (D), Elif ONBAŞ ${ }^{1}$
}

\begin{abstract}
Ensuring food safety is becoming progressively important in frozen foods due to increased demand and consumption worldwide. The Environmental Monitoring Program (EMP) shall support daily operational activities and monitor the lack of process hygiene \& sanitation actions to achieve food safety. The aim of this study was implementation of EMP in the frozen fruit and vegetable factory to identify the place that allows for pathogen/indicator microorganism growth and create preventive actions to reduce or eliminate the risk of cross- contamination. A total of 400 swab samples, Zone $1(n=228)$, Zone $2(n=90)$, Zone 3 $(\mathrm{n}=52)$, Zone $4(\mathrm{n}=30)$ were examined for E. coli and Coliform, Total Plate Count (TPC), yeast and mold and environmental Listeria spp. The percentage of satisfying target value before vs after the implementation of EMP was $82 \%$ vs. $100 \%$ for E. coli, $61 \%$ vs. $86 \%$ for Coliforms, $48 \%$ vs. $77 \%$ for TPC and $63 \%$ vs. $80 \%$ for yeast \& mold respectively for Zone 1 . Environmental Listeria was not determined in any of the zones. Integration of EMP to food safety management systems is essential to prevent outbreaks, recalls and economic losses. In addition to depending on the developing technologies, EMP should be supported with new corrective actions.
\end{abstract}

Keywords: environmental monitoring program (EMP); frozen fruits and vegetables; pathogen microorganisms (PMO); food safety.

Practical Application: Monitoring, controlling and preventing of bacterial contamination using EMP program.

\section{Introduction}

Recently, the trend of frozen foods has been increasing worldwide due to globalization and busy lifestyle. Also, the reason for the preference is that these products can be stored and used for a long time and preserving the nutritional value. Nowadays, the global frozen food market is one of the major sectors of the food industry, estimated to reach approximately $\$ 282.5$ billion by 2023 (Sowmya \& Samsai, 2019).

Food safety and quality of frozen fruits and vegetables is a crucial issue for public consumption. To be considered safe for consumption, frozen foods must meet: legal requirements, customer and hygiene requirements, trading conditions and satisfying their intended use. Therefore, compliance with strict quality systems is essential to ensure safe and quality production of frozen foods. According to the European Commission on regulation (2016/C 278/01) require implementation of a food safety system based on HACCP (Hazard Analysis Critical Control Point) for all food chain production (European Commission, 2016). HACCP is a scientific and effective system used to provide the safety of the product from raw material to final consumption (Domenech et al., 2008).

The basis of HACCP is the identification and evaluation of biological, chemical or physical hazards that have the potential to cause adverse health effects in foods. HACCP and the good manufacturing practices (GMP) applications are recommended to be applied together in all processes of food production for effective food safety system (Tomar \& Akarca, 2019). GMP are prerequisite programs which involve several aspects of the food industry, such as physical structure and maintenance, personal hygiene, pest control, sanitization techniques and equipment, calibration of instruments etc. (Kamboj et al., 2020). Chemical, sensory and microbiological parameters of products improve after GMP training and applications (Ramón et al., 2018). Although HACCP and GMP implemented in the majority of food facilities, recently foodborne outbreaks and diseases related with frozen industry have raised in global public health concern (Nasheri et al., 2019).

Foodborne diseases are generally caused by consumption of foods contaminated with pathogenic bacteria and/or their toxins, fungi, parasites, chemicals or other agents etc. Foodborne poisoning can significant public health problem due to the millions of cases experienced every year (World Health Organization, 2019). The federal government estimates that there are about 48 million foodborne diseases annually, resulting in about 128,000 hospitalizations and 3,000 fatalities (U.S. Food and Drug Administration, 2019a).

Listeria monocytogenes which is the most known pathogenic microorganism for frozen food cause severe infections and foodborne illness (Kase et al., 2017). It is considered a risky pathogen for public due to the high mortality rate of 20 to $30 \%$ (Swaminathan \& Gerner-Smidt, 2007). In light of recent outbreaks, frozen fruits and vegetables are considered one of the riskiest products in the frozen industry. As a sample, frozen green peas and corn were associated with an outbreak of L. monocytogenes which involved 9 patients from 2013 to 2016. 
According to the Food and Drug Administration (FDA), more than 350 products that sold marked under 42 brand names were recalled (Centers for Disease Control and Prevention, 2016). Between 2015 to 2018, L. monocytogenes caused the huge outbreak that 47 cases including nine deaths were reported and the company recalled products from more than 100 countries including the U.S. and Canada. After microbiological examination, similar strains of $L$. monocytogenes have been detected in some products that produced by the same company at different times (European Centre for Disease Prevention and Control, 2018). Moreover, the last recall was frozen spinach that expired date is on 12/03/2021 due to potential L. monocytogenes contamination in 2019 (U.S. Food and Drug Administration, 2019b).

On the other hand, a product recall is not only a public health concern but also cause huge economic losses. For example, the economic loss of per recall is estimated at nearly an average of $\$ 10$ million (Weigel, 2019). Moreover, brands can be seriously damaged due to product losses, loss of markets and consumer confidence.

IFS, BRC, ISO 22000/HACCP, etc. are modern food quality and safety management systems, but ongoing foodborne outbreaks and product recalls show that they are not sufficient alone for food safety. The implementation of EMP program is recommended in recent years to ensure safe food production, to prevent foodborne outbreaks, product recalls and major economic losses. According to FDA guidance for industry, a food-producing facilities that identify a potential environmental pathogen or indicator microorganism as a hazard to ready-to-eat (RTE) foods should include an EMP in food safety plans (U.S. Food and Drug Administration, 2015). EMP is a monitoring program that verifies the effectiveness of overall hygiene-sanitation practices and control programs (United Fresh Produce Association, 2018). Also, it provides key knowledge to the detection of possible cross-contamination sites of microorganisms in the production or non-production area. In order to effectively monitor microbial controls in the production area, the company must implement and maintain a well-designed EMP in addition to HACCP-based food safety systems. Moreover, EMP must be supported with appropriate corrective and preventive actions including cleaning, sanitation, and employee hygiene practices, etc. to eliminate microbial contamination risk.

Our aim of this study is implementation and verification of a well-designed EMP monitoring system in a frozen fruits and vegetables plant to determine potential sources of microbial contamination. This is the first report on the application of EMP to frozen foods and provides a scientific model to develop, apply and validate EMPs for this sector.

\section{Materials and methods}

\subsection{Study design and facility selection}

This study was conducted in close cooperation with a frozen fruit and vegetable factory that certified with the BRC Global Standard for Food Safety, located in the Aegean area of Turkey.
The facility produces approximately 3000 tons of frozen fruits and vegetables including pepper, spinach, broccoli, strawberry, cherry, sour cherry, etc. annually. The Integration of the EMP into the quality systems was done to ensure management of microbial safety. EMP was designed, developed and applied to the facility during the period between February 2018 and February 2019. Before arrangement of EMP, employees were trained about the content and purpose of program according to current EMP guidance (United Fresh Produce Association, 2018). The first step is creating a knowledgeable and multidisciplinary EMP team. Our team includes quality manager, microbiologist, production supervisor, line operators, maintenance operator, and sanitation workers.

\subsection{Sampling zones and sampling procedure}

The facility was initially visited and inspected by researchers of this study to evaluate individualized EMP sampling procedures and zones. Sample sites were divided into four zones from the highest risk (Zone 1) to lowest risk areas (Zone 4) according to the zone concept of EMP (Figure 1). The list of 43 sampling sites including from Zone 1 to Zone 4 is shown in Table 1. Zone 1 sites are surfaces that directly contact the product immediately after bleaching and just before packaging such as personnel hand, packing machine, elevator belt, color sorter machine, etc. Zone 2 sites are non-product contact surfaces that are physically quite close to the product (personal uniform, weighing scales, maintenance tools and lambs, etc.). Generally, environmental contaminants in these sites are likely hazards to affect the safety of the product. Zone 3 sites are indirect contact surface and further away from the product but still inside the manufacturing area including floors, walls and ceilings, drains, pallets, doors, and trash cans, etc. Zone 4 sites are outside of the production area (locker rooms, bathrooms, and office areas, etc. (United Fresh Produce Association, 2018; Simmons \& Wiedmann, 2017). This zone needs to be well maintained as much as the other zones mentioned above to prevent the risk of microbiological cross-contamination.

\subsection{Sampling and analysis}

The previous year's environmental microbiological swab results were examined to determine indicator microorganisms and establish frequency/target values (Table 2). The European Commission suggested microbial levels ranging from 0 to $10 \mathrm{CFU} / \mathrm{cm}^{2}$ on food equipment and food preparation surfaces in the production area (European Commission, 2001). 400 environmental samples were collected from Zone 1 $(\mathrm{n}=228)$, Zone $2(\mathrm{n}=90)$, Zone $3(\mathrm{n}=52)$ and Zone 4 $(\mathrm{n}=30)$ according to sampling frequency during one-year period (2018 to 2019). These samples were tested for E. coli and Coliform, Total Plate Count (TPC), yeast and mold and environmental Listeria spp. using BS ISO 18593:2018 (2018) method. Each sample was taken from nearly a $100 \mathrm{~cm}^{2}$ area by a swab stick. All samples were placed in sterile bags and transported to the microbiology laboratory at low temperature and were analyzed within $24 \mathrm{~h}$ after sampling. Table 3 shows the microbiological parameters investigated and relative identification techniques. 


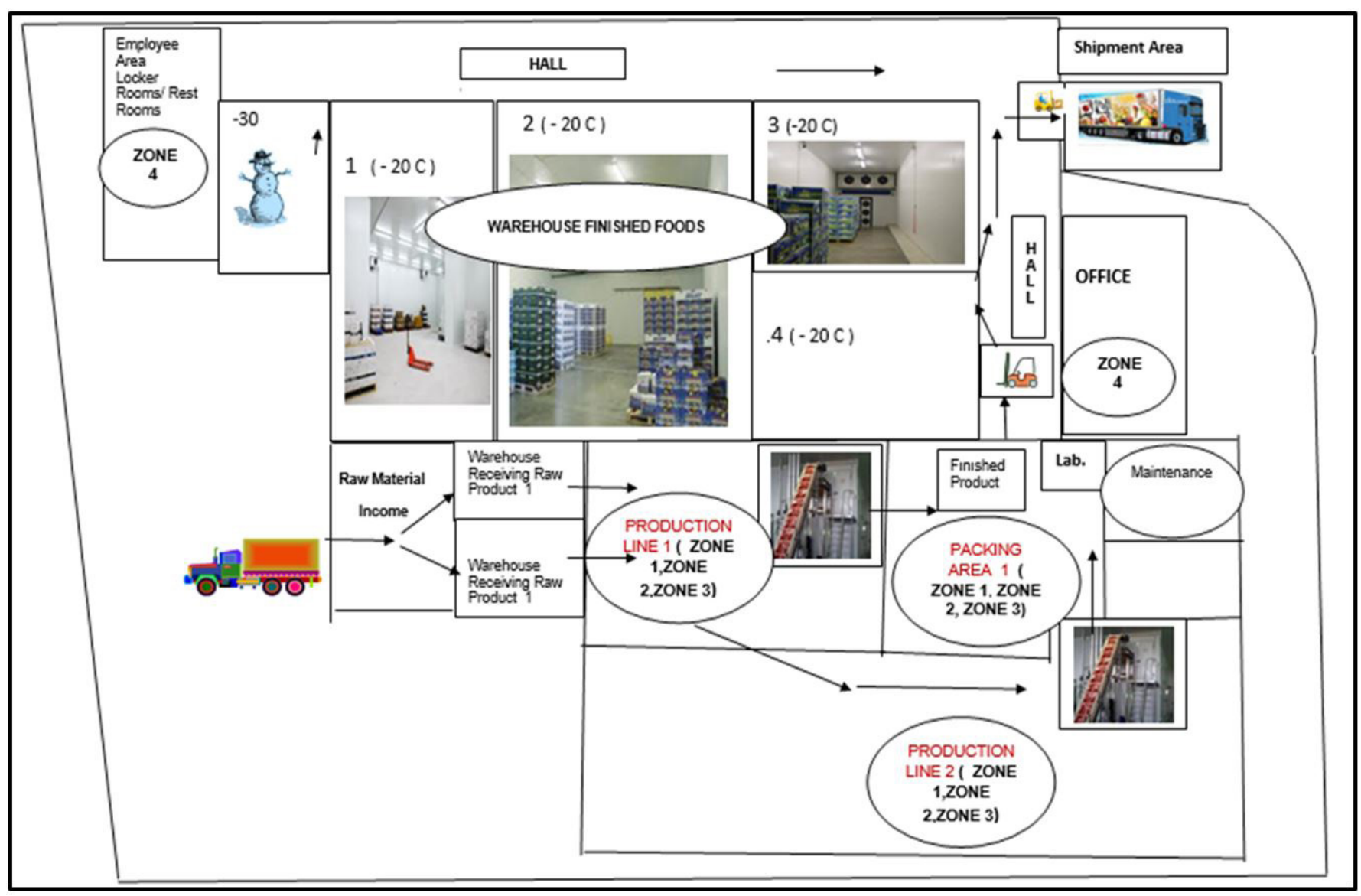

Figure 1. Mapping of zones in the factory. Zoning concept to illustrate areas of highest risk (Zone 1) to lowest risk (Zone 4) for product contamination.

Table 1. EMP sampling location for each zone.

\begin{tabular}{cccc}
\hline Zone 1 & Zone 2 & Zone 3 & Zone 4 \\
\hline Personnel Hand & Personal Uniform & Metal Detector & Locker Room \\
Packing Machine & Weighing Scales & Cold Storage Rooms & Cafeteria \\
Packing Material & Maintenance tools & Floors & Bathrooms \\
Elevator Belt & Lambs & Walls & Hallways \\
Color Sorter Machine & Cardboard Box & Doors & Office Areas \\
Conveyor Belts & Machine Buttons & Drains & Maintenance room \\
IQF Machine & Equipment Frameworks & UV Flapper & Glasses \\
Vibrating Screen & IQF Screen & Pallets & Trash Containers \\
Cutting Machine & Color Sorter Screen & Foot mats & Trolleys \\
Blanching Machine & & Forklifts & \\
Primary Packing Material & & Ventilation equipment & \\
Thermometers & & & \\
Air & & &
\end{tabular}

IQF: Individual Quick Freezing; UV: Ultraviolet.

\section{Results and discussion}

In this study, the frozen facility was examined on their environmental microbiological status during the EMP system implementation period (between February 2018 and February 2019). The sampling site list that was formed based on guidance documents and included 14 sites in Zone 1, 9 sites in Zone 2, 14 sites in Zone 3, and 6 sites in Zone 4 (Table 1). Detailed research was carried out previous year historical data of microbiological swap results in order to determine which the pathogen and indicator microorganisms that may be present in the facility. After the cleaning-sanitation program application, 400 samples were collected and tested for E. coli and Coliform, Total Plate Count (TPC), yeast and mold and environmental Listeria spp. during the EMP period. 
As shown in Table 4, before the implementation of EMP satisfying percentage was $82 \%, 61 \%, 48 \%, 63 \%$ and $100 \%$ for E. coli, Coliform, Total Plate Count (TPC), yeast and mold and environmental Listeria spp. respectively. Comparatively, the percentage of post-EMP analysis results were $100 \%, 86 \%, 77 \%$, $80 \%, 100 \%$ respectively for Zone 1 .

Prior to EMP, the presence of E. coli showed that there were unfavorable hygiene conditions and fecal contamination which occur via staff hand and/or uniforms on the facility. Many strains of E. coli are known to be harmless to humans, but some can cause serious foodborne disease. Fuerst (1983) stated that staff hands can be vectors in the spread of foodborne illness because of cross-contamination. Firstly, swab samples were taken from the hands and clothes of the employee to monitor detect the microorganism. We observed that employee's hand washing length of time was not enough to eliminate the microorganism. The water temperature problem, which was the root cause of this phenomenon, solved with the help of heater accents integrated into the facility. One of the other findings, it was noticed that the disinfectant was diluted by employees due to irritating their hands, thereby reducing sanitize effect. This problem was solved by using an alcohol-based hand sanitizer, which is less odor and irritant, to reduce the infectious microorganism at hand. In addition, employees were trained on where E. coli originated, how to wash hands (length of time, method, use of soap etc.) and how to use personal protective equipment such as uniforms and gloves (frequency of changing gloves) hygienically. In training, emphasized that good personal hygiene practices provide being healthier staff, the product also pleasant factory and customer. Moreover, the uniforms were washed by trained personnel with odorless chemicals in the laundry where was established in facility. As shown in Table 4 that the E. coli results are negative after EMP application. The improvement in the microbiological quality indicated that corrective actions were appropriate.

Our satisfying results before and after EMP were $61 \%$ and $86 \%$ for Coliforms in Zone 1, respectively (Table 4). Detection of Coliform bacteria higher than target levels on surfaces in the production environment was indicated that inadequate cleaning and sanitation practices and potential microbiological contamination occurred. Sanitizing problems were identified,

Table 2. EMP sampling frequency, number of samples per zone, type of microorganisms, target value after sanitation.

\begin{tabular}{|c|c|c|c|}
\hline Zone - Place & Frequency of Testing Swab & $\begin{array}{c}\text { Typical Number of } \\
\text { Sample }\end{array}$ & Analysis microorganism-Target Value \\
\hline Zone 3 & $\begin{array}{l}\text { Monthly, Increase testing frequency } \\
\text { unsuitable situations }\end{array}$ & $5-8$ & $\begin{array}{l}\text { TPC, Coliform, yeast and mold }<10 \mathrm{CFU} / \mathrm{cm}^{2} \text { for All Zones. } \\
\text { Listeria and E. coli Negative }\end{array}$ \\
\hline
\end{tabular}

CFU: Colony Forming Unit; TPC: Total Plate Count.

Table 3. Microbiological parameters investigated and relative identification techniques.

\begin{tabular}{lccc}
\hline \multicolumn{1}{c}{ Species name } & Agar name & Incubation time $(\mathrm{h})$ & Incubation temperature \\
\hline E. coli and Coliform & CCA & 24 & $37^{\circ} \mathrm{C}$ \\
TPC & PCA & 48 & $37^{\circ} \mathrm{C}$ \\
Yeast and Mold & DRBC & 120 & $25^{\circ} \mathrm{C}$ \\
Environmental Listeria & $3 M^{\text {st }}$ Petrifilm & 28 & $37^{\circ} \mathrm{C}$ \\
\hline
\end{tabular}

TPC: Total Plate Count; CCA: Chromocult Coliform Agar; PCA: Plate Count Agar; DRBC: Dichloran Rose Bengal Chloramphenicol.

Table 4. Percentage of Zone 1 surfaces swap results meeting the target microbiological value pre-EMP and post-EMP.

\begin{tabular}{|c|c|c|c|c|}
\hline $\begin{array}{l}\text { Sampling } \\
\text { Points }\end{array}$ & $\begin{array}{l}\text { Microbiological } \\
\text { parameter }\end{array}$ & Sampling Period & No of samples & $\begin{array}{c}\text { Percentage of surfaces swap results } \\
\text { meeting target }<10 \mathrm{CFU} / \mathrm{cm}^{2}(\%)\end{array}$ \\
\hline \multirow[t]{10}{*}{ Zone 1} & TPC & Feb 2017-Feb 2018 & Pre-EMP $145^{\mathrm{a}}$ & 48 \\
\hline & Yeast \& Molds & Feb 2018-Feb 2019 & Post-EMP $228^{\mathrm{b}}$ & 77 \\
\hline & E. coli & Feb 2017-Feb 2018 & Pre-EMP 145 & 63 \\
\hline & Coliform & Feb 2018-Feb 2019 & Post-EMP 228 & 80 \\
\hline & Environmental & Feb 2017-Feb 2018 & Pre-EMP 145 & 82 \\
\hline & Listeria spp. & Feb 2018-Feb 2019 & Post-EMP 228 & 100 \\
\hline & & Feb 2017-Feb 2018 & Pre-EMP 145 & 61 \\
\hline & & Feb 2018-Feb 2019 & Post-EMP 228 & 86 \\
\hline & & Feb 2017-Feb 2018 & Pre-EMP 145 & Absence \\
\hline & & Feb 2018-Feb 2019 & Post-EMP 228 & Absence \\
\hline
\end{tabular}

TPC: Total Plate Count; CFU: Colony Forming Unit. ${ }^{a}$ The total number of analyses in one- year historical data for zone 1 before implementation EMP; ${ }^{\mathrm{b}}$ The total number of analyses in one-year for zone 1 after implementation EMP. 
including sanitizer concentration and water temperature lack of control, utilizing dirty tools in cleaning in addition to the application of non-effective cleaning programs, etc. Proper cleaning and sanitation procedures/practices were re-designated for all food contact surfaces (Zone1) as well as for non- contact surfaces/areas (Zone 2,3,4) and every parameter which effected food hygiene and safety. Therefore, the foam system with an automatic disinfectant dosage was integrated in this facility to enable effective and low-cost cleaning of surfaces. Used disinfectant types, dosage and contact time with equipment surface were determined based on microbiological swaps results which were taken before and after disinfection.

After the implementation of the EMP system, TPC count in Zone 1 was reduced and the satisfaction percentage reached from forty-eight to seventy-seven (Table 4). Surfaces and areas with high a microbial load such as floors, walls, and drains were identified as high-risk areas during the EMP period. Hence the EMP program showed that non-product contact surfaces or areas are likely to be a source of cross-contamination. The surfaces not included in the cleaning plan were integrated into the sanitation program, thereby reducing TPC values.

Sixty-three and eighty percentage of samples were found to have yeast and mold before and after the implementation of the EMP system, respectively (Table 4). Observed mold and yeasts were particularly associated with the surface of the equipment which had dead points, cannot be cleaned completely and containing food residue accumulation after cleaning. Equipment's surfaces were re-designed to prevent yeast and mold ingress, growth on both product and non-product contact surfaces. The equipment surfaces which are easily accessible for cleaning and sanitation should be free of cavities such as pits and dead point also slope to avoid residue accumulation point.

The environmental Listeria spp. threat has not been observed in this facility owing to applied all cleaning and sanitation programs, personnel training and corrective and preventive actions. Moreover, the results of the analysis are given for Zone 2, Zone 3 and Zone 4 after application EMP in Table 5, Table 6, Table 7 , respectively.

This study is the first report for frozen fruit and vegetable industries and provides key- information that can be used by the food industry for the improvement and application of a scientifically supported EMP system. Overall, our data indicate that these were a significant reduction in the microorganism after the implementation of the EMP system. This is similar to findings by Zacharski et al. (2018) that reported an environmental monitoring program plays an important role in the control of microbiological hazards in a dairy plant environment. In another study in small cheese processing facilities suggests that appropriately implemented EMPs may reduce the risk of pathogen detection (Beno et al., 2016).

Table 5. Percentage of Zone 2 surfaces swap results meeting the target microbiological value post-EMP.

\begin{tabular}{ccccc}
\hline Sampling Points & $\begin{array}{c}\text { Microbiological } \\
\text { parameter }\end{array}$ & Sampling Period & No of samples & $\begin{array}{c}\text { Percentage of surfaces } \\
\text { swap results meeting } \\
\text { target }<10 \text { CFU/ } \mathrm{cm}^{2}(\%)\end{array}$ \\
\hline Zone 2 & TPC & Feb 2018-Feb 2019 & Post-EMP 90 & 72 \\
& Yeast \& Molds & Feb 2018-Feb 2019 & Post-EMP 90 & 76 \\
E. coli & Feb 2018-Feb 2019 & Post-EMP 90 & 100 \\
82 & Post-EMP 90 & Absence \\
\hline
\end{tabular}

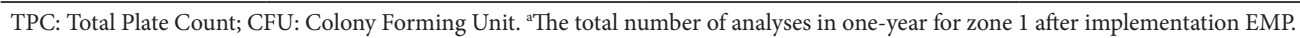

Table 6. Percentage of Zone 3 surfaces swap results meeting the target microbiological value post-EMP.

\begin{tabular}{|c|c|c|c|c|}
\hline $\begin{array}{l}\text { Sampling } \\
\text { Points }\end{array}$ & $\begin{array}{l}\text { Microbiological } \\
\text { parameter }\end{array}$ & Sampling Period & No of samples & $\begin{array}{c}\text { Percentage of surfaces } \\
\text { swap results meeting } \\
\text { target }<10 \mathrm{CFU} / \mathrm{cm}^{2}(\%)\end{array}$ \\
\hline \multirow[t]{4}{*}{ Zone 3} & TPC & Feb 2018-Feb 2019 & Post-EMP 52a & 76 \\
\hline & E. coli & Feb 2018-Feb 2019 & Post-EMP 52 & 100 \\
\hline & Coliform & Feb 2018-Feb 2019 & Post-EMP 52 & 84 \\
\hline & Environmental Listeria spp. & Feb 2018-Feb 2019 & Post-EMP 52 & Absence \\
\hline
\end{tabular}

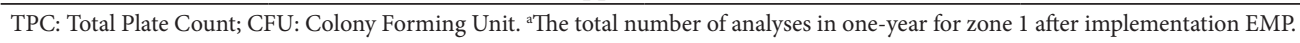

Table 7. Percentage of Zone 4 surfaces swap results meeting the target microbiological value post-EMP.

\begin{tabular}{ccccc}
\hline $\begin{array}{c}\text { Sampling } \\
\text { Points }\end{array}$ & $\begin{array}{c}\text { Microbiological } \\
\text { parameter }\end{array}$ & Sampling Period & No of samples & $\begin{array}{c}\text { Percentage of surfaces } \\
\text { swap results meeting } \\
\text { target }<10 \mathrm{CFU} / \mathrm{cm}^{2}(\%)\end{array}$ \\
\hline Zone 4 & TPC & Feb 2018-Feb 2019 & Post-EMP 30 & 74 \\
& Yeast \& Molds & Feb 2018-Feb 2019 & Post-EMP 30 & 83 \\
& E. coli & Feb 2018-Feb 2019 & Post-EMP 30 & 100 \\
& Coliform & Feb 2018-Feb 2019 & Post-EMP 30 & 88 \\
Environmental Listeria spp. & Feb 2018-Feb 2019 & Post-EMP 30 & Absence \\
\hline
\end{tabular}

\footnotetext{
TPC: Total Plate Count; CFU: Colony Forming Unit. ${ }^{a}$ The total number of analyses in one-year for zone 1 after implementation EMP.
} 


\section{Conclusion}

Safe food is defined as uncontaminated food at any point during the growth, processing, storage, sale or service of food. Contamination generally occurs from poor personal hygiene, inefficient cleaning and sanitation practices. EMPs are designed to evaluate the effectiveness of hygiene and sanitation practices in food facilities and provide valuable information to prevent cross-contamination. The sustainability of this system is as important as the establishment of the EMP system. A monitoring system, EMP should be supported by preventive and corrective actions such as modification in equipment design, cleaning and disinfection procedures, and personnel practices to achieve safe food production.

IFS, BRC, ISO 22000/HACCP, etc. are modern food quality and safety management systems, but ongoing foodborne outbreaks and product recalls show that they are not sufficient alone for food safety. Integration of EMP in food quality and safety system is essential for safe food production, to prevent foodborne outbreaks, product recalls and major economic losses.

\section{References}

Beno, S. M., Stasiewicz, M. J., Andrus, A. D., Ralyea, R. D., Kent, D. J., Martin, N. H., Wiedmann, M., \& Boor, K. J. (2016). Development and validation of pathogen environmental monitoring programs for small cheese processing facilities. Journal of Food Protection, 79(12), 2095-2106. http://dx.doi.org/10.4315/0362-028X.JFP-16241. PMid:28221969.

Centers for Disease Control and Prevention - CDC. (2016). Multistate outbreak of listeriosis linked to frozen vegetables - final update. Atlanta: CDC.

Domenech, E., Escriche, I., \& Martorell, S. (2008). Assessing the effectiveness of critical control points to guarantee food safety. Food Control, 19(6), 557-565. http://dx.doi.org/10.1016/j.foodcont.2007.06.015.

European Centre for Disease Prevention and Control - ECDC. (2018). Rapid risk assessment: multi-country outbreak of Listeria monocytogenes serogroup IVb, multi-locus sequence type 6, infections linked to frozen corn and possibly to other frozen vegetables - final update. Suécia: ECDC.

European Commission - EC. (2001, June 8). Comission Decision of 8 June 2001 laying down rules for the regular checks on the general hygiene carried out by the operators in establishments according to Directive 64/433/EEC on health conditions for the production and marketing of fresh meat and Directive 71/118/EEC on health problems affecting the production and placing on the market of fresh poultry meat. Official Journal of the European Communities.

European Commission - EC. (2016). Commission Notice on the implementation of food safety management systems covering prerequisite programs (PRPs) and procedures based on the HACCP principles, including the facilitation/flexibility of the implementation in certain food businesses. Official Journal of the European Communities.

Fuerst, R. (1983). Sanitation food handling. In M. Frobisher. Frobisher and Fuerst's microbiology in health and disease: foods as vectors of microbial disease (pp. 418-433). Philadelphia: W.B. Saunders Company.
ISO 18593:2018. (2018). Microbiology of the food chain - Horizontal methods for surface sampling. Retrieved from https://www.iso.org/ standard/64950.html.

Kamboj, S., Gupta, N., Bandral, J. D., Gandotra, G., \& Anjum, A. (2020). Food safety and hygiene: a review. International Journal of Chemical Studies, 8(2), 358-368. http://dx.doi.org/10.22271/ chemi.2020.v8.i2f.8794.

Kase, J. A., Zhang, G., \& Chen, Y. (2017). Recent foodborne outbreaks in the United States linked to a typical vehicles lessons learned. Current Opinion in Food Science, 18, 56-63. http://dx.doi.org/10.1016/j. cofs.2017.10.014.

Nasheri, N., Vester, A., \& Petronella, N. (2019). Foodborne viral outbreaks associated with frozen produce. Epidemiology and Infection, 147, 291. http://dx.doi.org/10.1017/S0950268819001791. PMid:31625499.

Ramón, A. N., De La Vega, S. M., Ferrer, E. C., Cravero Bruneri, A. P., Millán, M. P., Oliveira, E. G., Borelli, M. F., Villalva, F. J., \& Paz, N. F. (2018). Training small producers in Good Manufacturing Practices for the development of goat milk cheese. Food Science and Technology (Campinas), 38(1), 134-141. http://dx.doi.org/10.1590/1678-457x.02017.

Simmons, C. K., \& Wiedmann, M. (2017). Identification and classification of sampling sites for pathogen environmental monitoring programs for Listeria monocytogenes: results from an expert elicitation. Food Microbiology, 75, 2-19. http://dx.doi.org/10.1016/j.fm.2017.07.005. PMid:30056959.

Sowmya, S., \& Samsai, T. (2019). Consumers' perception towards frozen meat products in Coimbatore city. International Journal of Education and Management Studies, 9, 78-81.

Swaminathan, B., \& Gerner-Smidt, P. (2007). The epidemiology of human listeriosis. Microbes and Infection, 9, 1236-1243.

Tomar, O., \& Akarca, G. (2019). Critical control points and food pathogen presence in dairy plants from Turkey. Food Science and Technology (Campinas), 39(2), 444-450. http://dx.doi.org/10.1590/fst.29717.

U.S. Food and Drug Administration - FDA. (2015). FSMA final rule for preventive controls for human food. Current good manufacturing practice and hazard analysis and risk-based preventive controls for human food. Maryland: FDA.

U.S. Food and Drug Administration - FDA. (2019a). Food safety: importance for at-risk groups. Maryland: FDA.

U.S. Food and Drug Administration - FDA. (2019b). Sprouts farmers market recalls frozen cut leaf spinach and frozen organic cut leaf spinach 16oz. Packages because of possible health risk. Maryland: FDA.

United Fresh Produce Association. (2018). Guidance on environmental monitoring and control of Listeria for the fresh produce industry second education. Washington: United Fresh Produce Association.

Weigel, G. (2019). The true costs of food recalls. Smart sense food safety. Retrieved from: https://blog.smartsense.co/costs-of-food-recalls

World Health Organization - WHO. (2019). Food safety. Geneva: WHO. Retrieved from: https://www.who.int/news-room/fact-sheets/ detail/food-safety

Zacharski, K., Southern, M., Ryan, A., \& Adley, C. (2018). Evaluation of an environmental monitoring program for the microbial safety of air and surfaces in a dairy plant environment. Journal of Food Protection, 81(7), 1108-1116. http://dx.doi.org/10.4315/0362-028X. JFP-17-464. PMid:29916731. 